\title{
0 conceito de letramento e as práticas de alfabetização
}

\author{
Marcelo Macedo Correa e Castro
}

Professor da Faculdade de Educação da UFRJ

Rejane Amorim

Professora da Faculdade de Educação da UFRJ

Luciene Cerdas

Professora da Faculdade de Educação da UFRJ

\section{Resumo}

Neste artigo, traça-se um percurso na compreensão do conceito de letramento, que suscita debates em torno do significado da alfabetização e se consolida como uma perspectiva possível para o ensino da leitura e da escrita. $\mathrm{O}$ texto resulta de atividades de pesquisa, ensino e extensão realizadas pelos autores com foco no ensino da escrita e na formação de professores, a partir de inquietações sobre o tema, levando em conta seu impacto tanto nos estudos como nas práticas docentes. A discussão proposta baseia-se em diversos autores que tratam sobre letramento na história recente. Esse recorte teórico permite apresentar um panorama atual da temática que se constitui como uma crítica em relação ao uso do termo letramento e sobre a dicotomia gerada no ensino da língua escrita, que insiste em separar o ensino do código dos seus sentidos em práticas pedagógicas que se dizem inovadoras.

Palavras-chaves: Alfabetização, letramento, ensino

\section{Abstract}

The concept of literacy and the practices of reading and writing

This article presents a methodological approach developed for the work with reading and writing in the school context, the Circuit of Diversified Activities (DAC). The principles and guidelines of pedagogical work stand out, emphasizing them as elements capable of qualifying literacy practices from collaborative processes. It ends by presenting tensions: the schooling process and the social practices of reading and writing, which lead to the protagonism of students in the literacy cycle; school purposes and extracurricular purposes, which deal with the conditions of use of language in and out of school; durable knowledge and preservation of meaning in reading and writing, focusing on the importance of the training of readers and writers.

Keywords: collective study activity; pedagogical mediations; group interaction. 


\section{Resumen}

\section{El concepto de letramiento y las prácticas de alfabetización}

En este artículo, trazamos un recorrido em la comprensión del concepto de letramiento, que suscita debates en torno al significado de la alfabetización y se consolida como una perspectiva posible para la enseñanza de la lectura y de la escritura. Como resultado de nuestras inversiones em investigación, enseñanza y extensión em la enseñanza de la escritura y en laformación de profesores, comenzaremos por presentar el posicionamiento de diversos autores sobre letramento en la historia reciente, teniendo en cuenta su impacto tanto en los estudios como en las prácticas docentes. Este recorte teórico permite presentar una crítica en relación al uso del término letramiento y sobre la dicotomía generada en la enseñanza de la lengua escrita, que separa el código de sus sentidos en prácticas pedagógicas que se dicen innovadoras.

Palabrasclaves: Alfabetización, letramiento, enseñanza

\section{Introdução}

Há muitas discussões possíveis quando se trata da temática do ensino da leitura e da escrita. Neste artigo, traçamos um percurso teórico na compreensão do conceito de letramento, que suscita debates em torno do significado da alfabetização e se consolida como uma perspectiva possível para o ensino da leitura e escrita. Como resultado de nossos investimentos contínuos em pesquisa, ensino e extensão no ensino da escrita e na formação de professores no âmbito da universidade, começaremos por apresentar o posicionamento de diversos autores sobre letramento na história recente (e.g. SMOLKA, 2012, GERALDI, 2011, FERREIRO, 2003, SOARES, 1998), levando em conta seu impacto tanto nos estudos acadêmicos como nas práticas docentes.

Não reduzindo a uma única perspectiva toda a complexa trama histórica e política que envolve oprocesso de alfabetização e seu entendimento, discussão além dos limites traçados para este texto, ponderamos sobre o quanto a posição veiculada por pesquisadores, universidades e publicações sobre o letramento interfere nas práticas educacionais. A mudança de uma prática já consolidada na escola para outra forma de ensinar, sobre a qual não se tem clareza e, mais que isso, que não foi construída junto aos professores que estão alfabetizando, pode gerar mais embaraços e dificuldades nos processos didáticos que vislumbrem atender a nomenclaturas e discussões do momento.

No século $\mathrm{XX}$, em especial em suas décadas finais, a alfabetização vivenciou uma diversidade de discussões produzidas a partir do crescente desenvolvimento 
de estudos e pesquisas em áreas como a Pedagogia, a Psicologia e a Linguística, que impactaram a compreensão que temos hoje sobre o processo de ensino e aprendizagem da leitura e da escrita. Construiu-se, por exemplo, um consenso de que a alfabetização não é um processo de desenvolvimento da decifração e da capacidade de grafar palavras, cujas práticas de ensino se limitariam ao ensino das letras e sons da língua na perspectiva do que é mais fácil ou mais difícil nessa aprendizagem. Colocaram-se em pauta discussões sobre a concepção de métodos; o processo pelo qual a criança se apropria da língua escrita; a natureza linguística do objeto de aprendizagem na alfabetização; as implicações desse processo em relação ao material didático; e a formação dos professores para a alfabetização.

Nesse sentido, é importante ressaltar que a história da alfabetização se confunde com a história dos métodos que até hoje influenciam a prática docente no ensino da leitura e da escrita, assim como com a das cartilhas, que se constituíram como material utilizado na escola para ensinar o aluno a ler e a escrever, orientando o trabalho do professor pela apresentação sequenciada das letras, sílabas ou palavras. Materiais com os quais a maioria de nós foi alfabetizada, em que predominava um ensino centrado no professor e baseado em exercícios mecânicos de repetição e memorização, a partir de atividades quase sempre sem significação para os alunos. Nada no trabalho previsto dizia respeito à aprendizagem da compreensão, que deveria vir sozinha a partir da aquisição do código, quase como consequência natural desse aprendizado. Em relação ao aluno, os métodos baseavam-se na ideia de que bastava a ele conhecer a estrutura da escrita (formas de organização e princípios fundamentais), para que desenvolvesse as atividades de leitura e produção escrita.

As críticas a esses métodos e práticas vão no sentido de que impossibilitariam a formação de indivíduos críticos e criativos, já que propõem a alfabetização por meio do trabalho com sílabas soltas, palavras isoladas ou frases sem sentido. Além disso, métodos que fomentam práticas baseadas no ideal da homogeneização, já que todos devem seguir os mesmos passos nesse processo, o que garantiria o sucesso na alfabetização. Aos que não atingem esse sucesso resta iniciar todo o processo, acumulando um histórico de fracasso escolar.

Dentre os estudos que contribuíram para a discussão e a ampliação do conceito de alfabetização destacamos os de Ferreiro e Teberoski (1979, 1986, 1990), que, apoiadas em teorias piagetianas, demonstraram como se desenvolve a capacidade de os sujeitos refletirem sobre a escrita, rompendo com a ideia de que a alfabetiza- 
ção é um processo puramente mecânico e aprendido na escola. As autoras identificaram, além das hipóteses de escrita construídas nesse processo, o quanto os estudantes já sabem sobre a escrita antes da alfabetização e que o reconhecimento desse saber deve ser o ponto de partida de qualquer trabalho pedagógico. Para essas autoras, cujos trabalhos são ainda hoje referências nas discussões sobre a alfabetização, o aluno, sujeito desse processo, define seus próprios problemas, constrói hipóteses e estratégias para resolvê-los. A criança procura ativamente entender a natureza da linguagem que se fala a sua volta e, para isso, formula hipóteses, busca regularidades, coloca à prova suas antecipações e cria sua própria gramática (FERREIRO; TEBEROSKY, 1999).

Nesse mesmo contexto, o século XX viu surgirem discussões em torno do conceito de letramento, resultantes da compreensão dos aspectos socioculturais da língua escrita, sendo pioneiros no Brasil os estudos de Kleiman (1995); Tfouni (1995) e Soares (2002). Embora já bastante divulgado, vale lembrar que o termo letramento abrange na perspectiva de Soares (2003) os conhecimentos, habilidades e atitudes que permitem a inserção dos indivíduos nas diferentes situações de uso da escrita, envolvendo a diferença entre saber ler e escrever e viver na condição ou estado de quem sabe ler e escrever.

A alfabetização em larga escala, decorrente da expansão do ensino público, passou a ser vista como uma questão de sobrevivência em todos os níveis das sociedades letradas, isto é, das “[ [..] sociedades organizadas em torno de um sistema de escrita [...] uma cultura cujos valores, atitudes e crenças são transmitidos por meio da linguagem escrita e que valoriza o ler e o escrever de modo mais efetivo do que o falar e o ouvir [...]” (MORTATTI, 2004, p. 98). O fracasso escolar é tratado, portanto, como uma ameaça às “[ $[.$.$] legítimas aspirações de uma democratização do saber$ e da cultura, que acompanhe a democratização do acesso à escola [...]” (SOARES; MACIEL, 2000, p.7). A alfabetização reafirma-se, assim, como um desafio para os pesquisadores e professores na busca pela qualidade do ensino, ou seja, de uma “[...] educação progressivamente ajustada ao aluno e aos apelos da sociedade letrada” (COLELLO, 2007, p.275).

Ao letramento, portanto, atribui-se a ressignificação do conceito de alfabetização, como veremos ao longo deste artigo. Como afirma Geraldi (2011, p.17): «Um novo conceito não vem sem seu aparato, sem produzir efeitos e sem oferecer soluções a problemas que outros conceitos não conseguiram sanar $[\ldots]$ », como responder às exigências e demandas sociais do uso da leitura e da escrita. Não basta mais ao indivíduo 
saber escrever seu nome ou um pequeno bilhete, pois as atividades cotidianas de uso da escrita tornam-se a cada dia mais complexas e frequentes, o que demanda um domínio mais efetivo do ler e escrever.

As discussões sobre o letramento vieram junto com uma reivindicação do rompimento com práticas de uso de textos e materiais sem sentido para os alfabetizandos, fossem eles crianças ou adultos. Os textos das cartilhas de alfabetização e outros materiais similares - muito conhecidos pela repetição de uma mesma família silábica com o objetivo de fixação do fonema e grafema (ex.: O dado é de Didi. Didi deu o dado ao Dudu), objetos de muitas controvérsias nas práticas escolares - agora ganhavam um novo elemento para discussão, uma vez que a forma de atender ao letramento na alfabetização deveria ponderar sobre a presença dos textos "verdadeiros" na sala de aula, ganhando destaque a perspectiva de uma prática de uso dos gêneros textuais que circulam na sociedade.

Documentos oficiais, e aqueles produzidos para a formação continuada de professores, reafirmam essa perspectiva ao apontarem que:

[...] em todos os anos de escolarização, a experiência com textos variados e de diferentes gêneros é fundamental para a constituição do ambiente de letramento. A seleção do material escrito, portanto, deve estar guiada pela necessidade de garantir aos alfabetizandos o contato com diversos textos e de facilitar a observação de práticas sociais de leitura e escrita nas quais suas diferentes funções e características sejam preservadas. Nesse sentido, os textos de literatura geral e infantil, jornais, revistas, textos publicitários, entre outros, são os modelos que se pode oferecer às crianças, jovens e adultos para que aprendam sobre a linguagem que se usa para escrever. (BRASIL, 1996, p. 151-2).

Materiais de formação de professores ainda indicam os melhores gêneros para se utilizar em sala:

As crianças, portanto, devem ser convidadas a ler, produzir e refletir sobre textos que circulam em diferentes esferas sociais de interlocução, mas alguns podem ser considerados prioritários como os gêneros da esfera literária; esfera acadêmica/escolar e esfera midiática destinadas a discutir temas relevantes. (BRASIL, 2012, p.32)

No entanto, a ideia de letramento, que por si levantou questões importantes 
sobre alfabetização e ensino da leitura e da escrita, merece atenção na medida em que pode limitar o processo de escrita. Rapidamente, o mercado editorial, ao aderir a essa perspectiva, apresenta materiais cujas características revelam exercícios com modelos e formatos limitados de diversos gêneros textuais, em nome do letramento, o que, em nossa percepção, contribui para silenciar a voz do sujeito que aprende.

Trazer para sala de aula os diferentes gêneros textuais é, sem dúvida, prática legítima e fundamental, no entanto, entendemos que essa presença nem sempre garante práticas efetivas de letramento e, mais ainda, nem mesmo de alfabetização no seu sentido mais estrito de domínio do sistema de escrita. Soares, em seu texto "Letramento e alfabetização: as muitas facetas”, fez uma crítica a essa concepção de que “aprender a ler e a escrever é aprender a construir sentido para e por meio de textos escritos, usando experiências e conhecimentos prévios; [...] pois sua aprendizagem decorreria de forma natural da interação com a língua escrita” (SOARES, 2003, p. 12), o que, segundo a autora, contribui para uma situação de fracasso escolar na alfabetização que se estende ao longo de toda escolarização.

Nesse sentido, se separamos a alfabetização, como sendo a aquisição do código, e a relação desse código com seus usos, como letramento, estamos compreendendo o sujeito que aprende como incapaz de refletir sobre a escrita e estabelecer relações entre o que está escrevendo e a leitura de mundo, referindo a ideia de Paulo Freire. Parece-nos bastante confuso, e pouco profícuo para as discussões sobre o ensino da leitura e escrita, pensar que ora se trabalha alfabetização, ora se trabalha letramento, como se fosse possível a qualquer processo de aprendizagem a ausência de relações. Sobretudo, o que nos inquieta, como professores e pesquisadores, é o espaço-tempo criado nessas práticas para que o sujeito escreva sobre o que deseja, para a escrita subjetiva e criativa, de tal modo que seu texto seja visto, nas palavras de Vygotsky (1988), como um microcosmos de significados.

\section{Concepções e entendimentos}

Segundo Soares (1998), três concepções de ensino têm orientado a evolução das práticas escolares de ensino-aprendizagem da leitura e da escrita: (1) a concepção fundante, que perdurou com vigor até os anos 1950, concebe a língua como sistema e se apoia na articulação das ações de descrever suas regras, ler os textos que empregam exemplarmente tais regras e escrever textos que sigam os modelos estudados; (2) a 
segunda, que concebe a língua como instrumento de comunicação e vigorou de fins dos anos de 1960 até meados da década seguinte, propõe o treinamento para contato com as diversas situações comunicacionais presentes no convívio social; (3) a terceira, que vem tentando se estabelecer desde fins dos anos 1970 e entende a língua como discurso, volta-se para ações que favoreçam a inserção dos estudantes nas práticas sociais de leitura e de escrita.

$\mathrm{Na}$ esteira do desenvolvimento da segunda e da terceira - sempre confrontadas pela primeira -, ganha espaço a noção de letramento, que passou a ter especial importância para as práticas escolares dos anos iniciais, com destaque para o processo de alfabetização, como destaca Sena (2014, p.67):

O campo do letramento e da alfabetização surge no Brasil há cerca de quarenta anos, a partir de uma série de políticas e movimentos públicos de reforma nas práticas de alfabetização. Desde seus primeiros momentos, o campo se orienta no sentido de trazer alternativas de superação dos estados recorrentes de fracasso em classes de alfabetização, especialmente nos sistemas públicos de ensino.

Retomando o histórico aqui já apresentado acerca da alfabetização, leitura e escrita, vale assinalar que, embora presente no discurso da literatura pedagógica dos últimos 50 anos, permanece necessária a crítica ao esvaziamento que as atividades de leitura e escrita assumiram nas práticas escolares. Parte da resposta a esse esvaziamento veio sob a forma da introdução do conceito de letramento como chave para um ensino que se deslocaria da descrição/imitação da norma padrão para as práticas sociais de leitura e de escrita.

Assim, a partir dos anos 1980/90, o termo letramento passou a ocupar discursos e textos acadêmicos como denominação preferencial de processos de ensinoaprendizagem das práticas sociais de leitura e escrita, em mais uma tentativa de fazer convergirem para o ensino de Língua Portuguesa concepções diversas, oriundas de várias perspectivas de estudo da língua em suas diferentes dimensões.

Se recuarmos mais na história e adotarmos um espectro mais amplo de uso da língua, encontraremos já a classificação dos membros de uma sociedade pelo seu nível de pertencimento à cultura letrada. Não por acaso, dispôs o Artigo $1^{\circ}$ da primeira lei geral de educação no Brasil, promulgada por D. Pedro I, em 15 de outubro de 
1827, que "Em todas as cidades, villas e logares mais populosos, haverão as escolas de primeiras letras que forem necessárias” (BRASIL, 1827).

A expressão “primeiras letras”, já presente em documentos anteriores à lei de 1827, integra uma coleção lexical radicada na palavra letra como sinônimo de pertencimento à cultura socialmente privilegiada pelos segmentos hegemônicos. Às “primeiras letras” juntam-se, por exemplo, o "beletrismo”, o "ser mais ou menos letrado” e a própria designação escolhida para distinguir o curso superior em que se formam especialistas em línguas e literaturas: Letras.

O Regimento da Faculdade de Letras da UFRJ, publicado em 1972, ao apresentar em seu Preâmbulo os princípios que sustentam a estrutura e o funcionamento da unidade, destaca em primeiro lugar a "compreensão de que o estudo de letras contribui poderosamente para o aperfeiçoamento do homem, razão por que adota a divisa: AD HOMINEM PER LITTERAS" (UFRJ, 1972, p.5), que significa “Ao homem pelas Letras” e já fora adotada como divisa da Faculdade de Letras da Universidade de Lisboa, fundada em 1911, para dar continuidade ao curso de Letras, criado em 1859 por D. Pedro V.

Não se trata, portanto, de um neologismo sem antecedentes na cultura brasileira nem, em especial, no universo da educação e das categorias com que se distinguem socialmente os cidadãos com base em seus respectivos capitais culturais. E neste sentido o pertencimento maior ou menor a esta cultura nunca se restringiu ao domínio das práticas sociais de leitura e de escrita, muito menos da forma como estas estão representadas/selecionadas/propostas em programas e materiais de ensino de Língua Portuguesa.

Tradução do inglês litteracy, o termo tem nesta tentativa de correspondência seu primeiro problema. De fato, o termo original, assim como o seu equivalente em francês e, mais ainda, a sua tradução no Português europeu - literacia - nomeia uma condição sociocultural mais complexa, em que o domínio das práticas de leitura e escrita constitui parte importante, mas cuja abrangência e capilarização não se esgotam nelas. Como já advertiram estudos diversos (e.g. SOARES, 2002, DIONÍSIO, 2006, GERALDI, 2011), o conceito de letramento parece deslizar e flutuar em sua significação, assumindo facetas nem sempre devidamente articuladas entre si.

Não sem motivo, portanto, vários autores tratam da complexidade do conceito de letramento. Começamos com Soares (2002), com o célebre "Letramento: um tema 
em três gêneros", no qual a autora empreende, dentre outros esforços, o de "discutir conceitos e, portanto, palavras, ou, se quiserem, vamos discutir palavras e, portanto, conceitos: os conceitos alfabetização e letramento; as palavras alfabetização e letramento” (p.29).

Por sua vez, Britto, no começo dos anos 2000, identifica a presença de três outras palavras, além de letramento: “alfabetismo, alfabetização e cultura escrita”, sendo um “simplismo supor que são todos equivalentes” (BRITTO, 2002, p.10). Para o referido autor, a proliferação desses termos estaria ligada a disputas político-ideológicas, uma vez que serviria para demarcar a oposição entre concepções de ensino-aprendizagem: de um lado, as vertentes mais técnicas e pretensamente apolíticas; de outro, as que entendem o processo em sua dimensão socioeconômica e/ou histórico-cultural.

Distinção semelhante apresenta Soares (2002), quando explica que há uma dimensão individual e outra social do letramento, e que este último, por seu turno, poderia ser de caráter liberal ou progressista, por ela denominado de letramento fraco, ou de cunho radical ou revolucionário, que a autora designou como letramento forte. A dimensão social, de acordo com Soares, considera o letramento como uma prática social, ou seja, é aquilo que as pessoas fazem com as habilidades de leitura e de escrita, nas práticas sociais, num determinado contexto, e como essas habilidades relacionamse com as necessidades e valores sociais.

Entre as suas contribuições, portanto, os estudos sobre o letramento lançam luzes sobre o aspecto social do aprendizado da leitura e da escrita, ao mesmo tempo em que apontam para novos desafios para a escola, quais sejam: levar o aluno não só à aquisição da tecnologia do ler e do escrever (alfabetizar), mas aos usos e práticas sociais da leitura e da escrita (letrar). Daí que aprender a ler e a escrever implica o conhecimento das letras e o modo de decodificá-las, mas também a possibilidade de usar esse conhecimento em situações legítimas em um determinado contexto cultural (COLELLO, 2004, p.110).

Ampliando o espectro das distinções, Dionísio (2006,p. 42) sustenta que:

As práticas de literacia na escola e as práticas de ensino da literacia estruturamse sobre um conjunto vasto de processos, activados por um largo número de dispositivos que produzem, numa determinada posição, os sujeitos que aí interagem "sobre textos, com textos e à volta de textos" (LUKE, 2001), com vista à aquisição e construção dos saberes escolares. Ao mesmo tempo, por tais processos e dispositivos produz-se e reproduz-se uma prática sociocul- 
tural que podemos reconhecer como própria deste "domínio de prática”: a escola. É o reconhecimento da acção de tais processos e dispositivos que cria a possibilidade de, ao falarmos, hoje, de literacia, o fazermos já no plural: literacias ou mesmo multiliteracias, literacias múltiplas, etc.; marca-se, por essa forma, a existência da especificidade das práticas que envolvem o escrito em múltiplos domínios da vida como, por exemplo, a família, os lugares de trabalho, a associação, etc.

De fato, no contex to europeu, onde atua a autora, a palavra literacia assumiu o lugar de uma espécie de catalizador de problemas sociais. Como comenta Lahire (2005, p.64), na França, “desde o final dos anos setenta, os «iletrados» se tornaram o símbolo por excelência da miséria, o iletrismo, o auge da pobreza, mesmo a causa de qualquer exclusão, especialmente econômica”. Essa posição é fortemente combatida pelo autor, quando apresenta uma pesquisa feita com estudantes da classe popular, na qual, em uma análise ampliada do problema, considera suas experiências de escrita na família, demonstrando o quanto o contato da escola com diversos gêneros foi importante para ampliar sua escrita nos diversos contextos, questões que a escola não consegue perceber, por causa da forma estanque e sedimentada com que trabalha e avalia a escrita (LAHIRE, 1997).

Retomando os autores brasileiros, encontramos em Geraldi (2011) uma crítica a essa ampliação dos significados do letramento. Para o autor, o termo passou a ser empregado para designar muitas dimensões do universo das práticas de leitura e de escrita, o que o levou a escrever que: "independentemente de adjetivos que possam lhe ser apostos, pode referir a estado ou condição, habilidades e aptidões, ao processo, ao uso de habilidades de leitura e escrita (o que quer que isso signifique)" (GERALDI, 2011, p. 20-1). Como consequência direta dessa ampliação em muitas direções, o autor considera "que o termo letramento sofreu um processo que o levou à sua "gaseificação", ou seja, "preenche tudo e nada ao mesmo tempo, o que o tornaria desnecessário". (GERALDI, 2011, p.20). Destaca ainda que a desnecessária presença explícita da leitura e da escrita nos eventos de letramento reforça essa gaseificação do conceito, levando à ideia de múltiplos letramentos, como "capacidades desenvolvidas pelo convívio com as diferentes esferas das atividades comunicacionais humanas".

Em posição mais extrema, Sena $(2014$, p.66) problematiza epistemologicamente a questão: 
Aliás, o campo do letramento e da alfabetização é, em si, um paradoxo para a epistemologia científica, seja ela de base teórica, seja empírica, pois que, em virtude da natureza singular e irredutível de cada uma das pessoas que desejamos ter como tal em sala de aula (e não, como sujeitos abstratos, reduzidos à noção universalista denominada aluno), não se podem operar ou derivar verdades que não sejam, cada qual, centradas e balizadas em um único sujeito, uma única pessoa.

Finalmente, em uma tentativa de recuperar o que poderia constituir um pertencimento mais específico do termo ao campo de estudos da língua, Cerutti-Rizzatti sustenta que:

(...) parece estar havendo uma ampliação desmedida do uso do termo letramento, estendido a esferas da convivência social nas quais o signo verbal escrito não se faz presente ou não é prevalecente; e, por outro lado, em um movimento oposto, parece ocorrer uma circunscrição desse mesmo uso, concebido à luz de perspectivas cognitivistas internalistas de língua escrita (CERUTTIRIZZATTI, 2012, p.292).

Assim como a autora, consideramos que a exagerada ampliação do conceito de letramento, bem como a suposta necessidade de conjugação das práticas de escrita às de leitura, levam a um esvaziamento das questões específicas que envolvem a escrita. Empregando as categorias identificadas por Orlandi (1983), seria possível sustentar que a reiterada paráfrase do termo letramento para sua fixação como categoria cientificamente operável parece ter sido suplantada pela polissemia, que tornou letramento um conceito instável e múltiplo.

O pressuposto de que não se pode desmarcar socialmente os usos da língua, nem apagar as condições socioeconômico culturais dos seus usuários, deve estar presente em quaisquer ações de ensino-aprendizagem e de investigação que envolvam a escrita. Isso, todavia, não pode ser o seu limite. Estudar a escrita com a compreensão de que está necessariamente inserida em um contexto social, ideologizado, marcado por disputas de poder não é o mesmo que limitá-la a este contexto.

O mesmo se aplica ao pressuposto igualmente necessário de que há relações viscerais entre leitura e escrita. Vale afirmar: adotar esse pressuposto, assumir que uma das marcas da escrita consiste justamente no fato de que ela dialoga com o que se leu, não justifica o aprisionamento das atividades de escrita às de leitura. 
O conceito de letramento, pois, além de amplo e rarefeito, ou gaseificado, remete, na melhor das hipóteses, a um contexto maior de uso social da língua, mas tem pouca consistência para abarcar as questões particulares da leitura e da escrita. Além disso, uma vez apropriado com os mais diferentes sentidos, acabou por fortalecer o movimento de retorno a visões limitadas e limitantes do processo de alfabetização.

Nesse sentido, Ferreiro (2003) rejeita o termo letramento ao afirmar que a alfabetização, como processo contínuo, incorpora, por si só, os preceitos desse conceito a partir de práticas que privilegiam a descoberta de usos e funções da escrita. Nessa mesma direção, Lerner (2002) aponta que a separação entre "apropriação do sistema de escrita” e “desenvolvimento da leitura e escrita” é um dos fatores responsáveis por uma prática centrada na sonorização e na decodificação, desvinculada do significado e da compreensão, que faz supor que a alfabetização seja um requisito prévio para que se possa perceber a função social do texto, ou a utilização da linguagem escrita como tal.

O necessário é fazer da escola um âmbito onde leitura e escrita sejam práticas vivas e vitais [...] preservar na escola o sentido que a leitura e a escrita têm como práticas sociais, para conseguir que os alunos se apropriem delas possibilitando que se incorporem à comunidade de leitores e escritores, a fim de que consigam ser cidadãos da cultura escrita (LERNER, 2002, p. 18).

Dessa forma, é esclarecedora a fala de Geraldi (2011) de que o conceito de letramento não tem ajudado a melhorar a compreensão dos processos de aquisição da língua escrita, e que tratar o ler e o escrever como codificar e decodificar exclui da linguagem sua razão de ser, qual seja, "os sentidos que mobilizam o homem, desde suas necessidades mais comezinhas até suas necessidades de rupturas com o já estabelecido, inclusive com a língua” (GERALDI, 2011, p.30).

Do ponto de vista do trabalho pedagógico dos alfabetizadores, Geraldi vem reforçar o que as pesquisas insistem em apontar, a permanência dos métodos que fazem a entrada na escrita pelo domínio do alfabeto e, só depois disso, propõem o exercício da compreensão e da interpretação de textos. Assim, o alfabetizar separa-se do letrar, embora em sua gênese o conceito de letramento tenha lançado luzes sobre mais uma faceta da alfabetização. A presença dessa perspectiva, no entanto, pareceu reforçar uma tendência clássica de que primeiro se alfabetiza para depois se ensinar de fato a ler e a escrever a partir da possibilidade real de utilização no cotidiano. Ou 
ao contrário, à medida em que os textos estejam presentes nas práticas de ensino, os alunos passariam a dominar as habilidades de escrita como consequência natural desse contato. Nos dois casos há equívocos cuja concretude do cotidiano escolar revela: ora a permanência de práticas baseadas em métodos que privilegiam o domínio do alfabeto como porta de entrada no ensino da leitura e da escrita e só depois trabalham com a compreensão e a interpretação, ora a ausência das atividades de aprendizagem do sistema de escrita alfabética em nome do letramento.

Alguns exemplos de pesquisas feitas nas escolas ajudam a esclarecer essa constatação. Nascimento (2017), em sua pesquisa sobre práticas de leitura, constatou que as práticas tradicionais convivem ao menos com:

[...] uma tentativa de se ensinar leitura literária nos anos iniciais, com livros infantis circulando no ambiente escolar, com as professoras lendo em voz alta para os alunos e tentando realizar diálogos sobre o texto, com as crianças levando livros emprestados para suas casas e até podendo frequentar a biblioteca da escola (quando o espaço está liberado).[...] A observação na escola confirmou o que outras pesquisas há muitos anos vêm testemunhando: a incorporação de "novidades" ou de práticas didáticas supostamente transformadoras em um esquema de ensino tradicional. (NASCIMENTO, 2017, p.14)

Constatação semelhante é apresentada no texto de Silva e Silva (2011), que identificaram uma perspectiva de prática de ensino da escrita em que, segundo as próprias professoras investigadas na pesquisa, o tradicional e o novo têm que caminhar juntos: mesclar as atividades ditas tradicionais com as mais atuais. O depoimento da professora, citado no texto de Da Silva e Silva e transcrito abaixo, esclarece tal concepção:

Embora eu ainda coloque algumas coisas do tradicional porque eu acho que todas colocam, como eu disse a você não tem aquela que não faça isso, por mais que você tente não fazer, mas você faz. [...] porque eu acho que precisa, porque eu acho que uma coisa completa a outra, o tradicional completa o... vamos dizer assim, o moderno. Eu penso assim! [...] você não pode deixar o tradicional pra trás de jeito nenhum, um completa o outro. (Neves, 40 anos, $2^{\mathrm{a}}$ série). (SILVA; SILVA, 2011, p. 12.)

Em outro estudo, Cruvinel (2010, p.4), ao analisar a metodologia utilizada em relação ao ensino da leitura, aponta que o gênero discursivo 


\footnotetext{
O conceito de letramento e as práticas de alfabetização

Marcelo Correa e Castro, Rejane Amorim e Luciene Cerdas
}

[...]é tomado pelo professor como objeto didático, não como instrumento de comunicação e de ensino da linguagem escrita, uma vez que é apresentado às crianças sem uma conexão com a realidade da atividade humana na qual se insere.Embora as crianças sejam informadas acerca do tipo de enunciado a ser lido e isso possa ser reconhecido como um avanço no ensino da leitura seria antes imprescindível propiciar situações de comunicação em que os aprendizes fizessem uso dos gêneros num processo discursivo.

Essa mesma constatação foi apresentada por Castro, Cerdas e Amorim (2017) na análise de materiais didáticos para alfabetização: exercícios de exploração dos grafemas e das sílabas das palavras; escrita prioritária de palavras e de frases; ausência de um trabalho voltado para o desenvolvimento da oralidade; atividades nas quais não é dada ao aluno a possibilidade de se aventurar na escrita espontânea de textos; atividades de leitura como pretexto para seleção de palavras-chaves no ensino do SEA; os textos apresentados aos alunos de forma fragmentada em diferentes lições, o que contribui para o empobrecimento do material de leitura.

Para as finalidades do nosso estudo, seja qual for o nome que se dê ao processo de aquisição e de uso da escrita, o que interessa de fato são algumas de suas marcas essenciais: é contínuo, é pessoal, é humano (portanto, social, ideológico, político, cultural), envolve múltiplas dimensões, é intransferível.

Também nos parece vazia a discussão sobre o lugar absoluto de uma suposta dimensão ou perspectiva técnico-instrumentalizadora. Essa abordagem remete ao superado mito da neutralidade científico-metodológica e à insustentável exclusividade das racionalizações no processo de escrita. É inegável que, no processo de aprendizagem e uso da escrita, há operações racionalizáveis e aspectos passíveis de descrição/ sistematização, isso, todavia, não nos autoriza a supor que eles possam ser dominados em um contexto neutro, desideologizado e despersonalizado.

Essa pretensão de isolar o técnico-cognitivo afeta particularmente a compreensão do processo de aquisição da escrita no caso da alfabetização, uma vez que há uma convicção generalizada de que, antes de começar para valer, o processo é precedido por uma etapa técnica, chamada alfabetização, para que se adquira um instrumental básico. O que Paulo Freire e outros defendem é justamente a percepção de que desde o seu início - que não se dá na escola - o processo é multidimensionado e referido na realidade socioeconômico-cultural do aprendiz, não havendo, pois, uma primeira etapa em que tudo se justifica porque ela seria "somente técnica". 
Em direção semelhante vai Camps (2005):

Uma ideia que importaria destacar é a da centralidade da palavra, do diálogo, nas acções humanas, entendendo-o no seu significado mais amplo, desde o que ocorre na interacção cara a cara na conversação, até ao que se estabelece entre todos os discursos produzidos ou antecipados. Os textos não são produtos fechados em si mesmos, pelo contrário, relacionam-se e projectam-se uns nos outros num diálogo permanente. Por este motivo, Bakhtin caracteriza a atividade humana e o discurso como dialógicos. Este tipo de atividade, a discursiva, é que é o especificamente humano. (CAMPS, 2005, p.19).

Trata-se, pois, de propor o ensino-aprendizagem de acordo com uma visão que considere as práticas sociais de linguagem como gestos de humanização no seu sentido mais pleno, e não somente treinamento ou aquisição de destreza para a aplicação de estruturas textuais formulaicas e modelos comunicacionais.

\section{Considerações finais}

Se, no campo conceitual, o letramento tem se configurado como um grande “guarda-chuva”, sob o qual se abrigam diferentes perspectivas, nas práticas, o letramento não reverbera de modo efetivo no dia a dia da alfabetização e do ensino da leitura e da escrita, figurando mais como um discurso esvaziado de sentido, que tende a fragilizar a organização do trabalho pedagógico de professores que buscam renovar suas práticas, muitas vezes, consideradas tradicionais.

Assim, o emprego múltiplo da noção de letramento, que parecia resolver muitas das questões téorico-práticas do ensino da escrita, parece ter esgotado suas possibilidades de contribuir para a superação dos limites historicamente construídos para esse ensino nas práticas escolares. O “novo” conceito acabou por contribuir para o retorno de concepções ultrapassadas de alfabetização, reforçando a fragmentação do ensino-aprendizagem da escrita. Assim, as vozes que defendiam antigas práticas de alfabetização foram favorecidas pela possibilidade de se deslocar os aspectos dialógicos e culturais do processo de ensino-aprendizagem da escrita para o abstrato e complexo universo do letramento, permitindo que a apropriação mecânica do Sistema de Escrita Alfabética voltasse a ocupar, de forma confortável, o lugar por excelência das "renovadas” práticas de alfabetização. 
Da mesma maneira, como caminho de concretização do letramento nas práticas seguintes à alfabetização, foi amplamente adotado o trabalho com gêneros textuais, como substituto preferencial dos programas estruturados com base no estudo da gramática normativa, sem que tal substituição vá muito além da esquematização de fórmulas para que os estudantes treinem a confecção de textos supostamente necessários às suas vidas, ainda que isso nem sempre esteja claro nas atividades de produção textual nas escolas.

Termos e nomenclaturas à parte, o que parece ainda por superar são concepções conservadoras de ensino-aprendizagem da escrita e das funções que historicamente ela tem assumido no processo civilizatório, de tal forma que novas palavras acabam tendo seus significados deslocados para a semântica mais conveniente à defesa de antigas práticas.

\section{Referências}

BRASIL. Ministério da Educação. Secretaria de Educação Básica. Pacto nacional pela alfabetização na idade certa: currículo na alfabetização: concepções e princípios: ano 1: unidade 1. Brasília, DF: Ministério da Educação, 2012.

BRASIL. Secretaria de Educação Fundamental. Parâmetros curriculares nacionais: língua portuguesa. Brasília, DF: MEC, SEB, 1996.

BRASIL. Lei de 15 de outubro de 1827. Lei do Império. Disponível em:<http://www2. camara.leg.br/legin/fed/lei_sn/1824-1899/lei-38398-15-outubro-1827-566692-publicacaooriginal-90222-pl.html>. Acesso em: 4 abr. 2018.

BRITTO, L. P. L. À sombra do caos: ensino de língua x tradição gramatical. Campinas: Mercado das Letras, 2002.

CAMPS, A. Pontos de vista sobre o ensino-aprendizagem da expressão escrita. In: ENCONTRO DE REFLEXÃO SOBRE O ENSINO DA ESCRITA, 2., 2005, Braga, 
Portugal.Actas... Braga: Instituto de Educação e Psicologia/Universidade do Minho, 2005. p. 11-26.

CASTRO, M. M. C.; CERDAS, L.; AMORIM, R. M A. Contextualização e práticas alfabetizadoras em debate: uso dos cadernos pedagógicos no município do Rio de Janeiro. In: EDUCERE "FORMAÇÃO DE PROFESSORES: CONTEXTOS, SENTIDOS E PRÁTICAS, 12., 2017, Curitiba, PR. Anais... Curitiba: Editora Universitária Champagnat, 2017.p.13542- 13558.

CERUTTI-RIZZATTI, M. E. Letramento: uma discussão sobre implicações de fronteiras conceituais. Educação e Sociedade, v. 33, n. 118, p. 291-305, jan.-mar. 2012. https://doi.org/10.1590/S0101-73302012000100018

COLELlO, S. M. G. A escola que (não) ensina a escrever. Rio de Janeiro: Paz e Terra, 2007.

Alfabetização em questão. 2. ed. Rio de Janeiro: Paz e Terra, 2004.

CRUVINEL, F. R. Ler na escola: as vozes das crianças. In:REUNIÃO ANUAL DA ANPED, 33., 2010, Caxambu, MG. Anais...Rio de Janeiro: ANPEd, 2010. p. 1-14.

DIONÍSIO, M. L. Facetas da literacia: processos da construção do sujeito letrado. Educação em Revista, v. 44, p. 41-67, dez. 2006. https://doi.org/10.1590/So10246982006000200003

FERREIRO, E. Alfabetização e cultura escrita: entrevista concedida à Denise Pellegrini. Nova Escola, p. 27-30, abr.- maio 2003.

FERREIRO, E. ; TEBEROSKY, A. Psicogênese da língua escrita. Porto Alegre: Ar- 
tes Médicas Sul, 1999.

GERALDI, J. W. Alfabetização e letramento: perguntas de um alfabetizador que lê. In: ZACCUR, E. (org.). Alfabetização e letramento: o que muda quando muda o nome? Rio de Janeiro: Rovelle, 2011.

KLEIMAN, A. (org.). Os significados do letramento: uma nova perspectiva sobre a prática social da escrita. Campinas: Mercado das Letras, 1995.

LAHIRE, B. Sucesso escolar nos meios populares: as razões do improvável. São Paulo: Ática, 1997.

L'invetion de l'illesttrime. Paris: La Découverte, 2005.

LERNER, D. Ler e escrever na escola: o real, o possível e o necessário. Porto Alegre:

Artmed, 2002.

LUKE, A. How to make literacy policy differently: generational change, professionalisation, and literate futures. In: JOINT NATIONAL AATE/ALEA CONFERENCE, Hobart, Tasmânia, 2001. \{S.n.t.].

MORTATTI, M. R. L. Educação e letramento. São Paulo: Unesp, 2004.

NASCIMENTO, I. S. Práticas de ensino de leitura literária nos anos

Iniciais: interações opacas, sentidos dissipados. In: REUNIÃO ANUALDA ANPED,38., 2017, São Luis, MA. Anais... Rio de Janeiro: ANPED, 2017. p. 1-16. 
ORLANDI, E. P. A linguagem e seu funcionamento: as formas do discurso. São Paulo: Brasiliense, 1983.

SENA, L. A. G. O campo acadêmico do letramento e da alfabetização no Brasil: estados e perspectivas da pesquisa em linguística aplicada. Revista Teias, v. 15, n. 38, p. $57-74,2014$.

SILVA, M. M.; SILVA, M. E. L. Representações sociais do ensino da língua escrita. Reunião Anual da ANPEd, 34, 201 1, Natal, RN. Anais... Rio de Janeiro: ANPEd, 2011. p. $1-15$.

SMOLKA, A. L. B. A criança na fase inicial da escrita: Alfabetização como processo discursivo. 13. ed. São Paulo: Cortez, 2012.

SOARES, M. Letramento: um tema em três gêneros. 3.ed. Belo Horizonte: Autêntica, 2002.

SOARES, M. Letramento e alfabetização: as muitas facetas. In: REUNIÃO ANUAL DA ANPED, 26., 2003, Poços de Caldas. Anais... Rio de Janeiro: Anped, 2003. p. 5-17.

SOARES, M.; MACIEL, F. (org.) Alfabetização. Brasília, DF: Ministério da Educação, 2000. (Série Estado do Conhecimento, vol. 1).

SOARES, M. B. Concepções de linguagem e o ensino de Língua Portuguesa. In: BASTOS, N. B. (org.). Lingua portuguesa: história, perspectivas, ensino. São Paulo: EDUC, 1998. p. 53-60. 
TFOUNI, L. V. Letramento e alfabetização. São Paulo: Cortez, 1995.

UNIVERSIDADE FEDERAL DO RIO DE JANEIRO. Faculdade de Letras. Regimento. Boletim, n.1, supl., 1972. Disponível em:<https://drive.google.com/file/d/oB23 bxlwjXLNaNG4wYlItRzRPMG8/view>. Acesso em: 24 ago. 2018.

VYGOTSKY, L. S. Pensamento e linguagem. São Paulo: Martins Fontes, 1988.

Submissão em: 05-04-2018

Aceite em: 22-08-2018 